\title{
Burnout syndrome among residents of different surgical specialties in a tertiary referral teaching hospital in Indonesia during COVID-19 pandemic
}

\author{
Besut Daryanto ${ }^{\text {a }}$, Nayla Rahmadiani ${ }^{\text {b, }}$, Reza Amorga ${ }^{a}$, Intan Kautsarani ${ }^{c}$, Hery Susilo ${ }^{\text {d, }}$ \\ Satria Pandu Persada Isma ${ }^{e}$
}

${ }^{a}$ Department of Urology, Saiful Anwar General Hospital, Malang, Indonesia

b Department of Anatomic Pathology, Saiful Anwar General Hospital, Malang, Indonesia

${ }^{c}$ Department of Ophthalmology, Saiful Anwar General Hospital, Malang, Indonesia

${ }^{\mathrm{d}}$ Department of Oncology Surgery, Saiful Anwar General Hospital, Malang, Indonesia

${ }^{\mathrm{e}}$ Department of Orthopedics, Saiful Anwar General Hospital, Malang, Indonesia

\section{A R T I C L E I N F O}

\section{Keywords:}

Burnout

Surgical residents

COVID-19

\begin{abstract}
A B S T R A C T
Introduction: Burnout is experienced frequently by residents, especially during COVID-19 pandemic. Impacts of the pandemic on clinical workload and training program of the residents has also resulted in burnout, which may impact their clinical performance and safety. Therefore, this paper aims to assess burnout syndrome among surgical residents in Indonesia during COVID-19 pandemic.

Methods: A cross-sectional survey was conducted on 120 surgical residents (from orthopedics, general surgery, and urology department) of a tertiary referral teaching hospital in Malang using web-based questionnaire. Personal data form and Maslach Burnout Inventory (MBI) for medical personnel were used. There are 3 subscales of MBI: emotional exhaustion (EE), depersonalization (DP), and personal achievement (PA). Comparative and correlative analysis were performed to analyze the socio-demographic, academic, and work-related factors in relation to the subscales scores of MBI-HSS and the presence of burnout.

Results: Burnout were experienced by $56.67 \%$ of residents in this study. There were statistically significant association regarding burnout and marital status, residency specialty, year of residency, and working hours upon analysis of mean and classification of subscale scores of MBI with the examined factors.

Conclusion: This study showed that burnout is a major issue in surgical residents during COVID-19 pandemic and may be associated with certain socio-demographic, academic, and work-related factors. Further studies to identify factors contributing to burnout in residents during COVID-19 pandemic are needed. It is imperative to formulate resident-centered strategies to prevent and address burnout among residents to ensure their overall well-being during this pandemic.
\end{abstract}

\section{Introduction}

Burnout is a term to be used within the context of describing stress experienced by an individual in association with occupational environment. It is defined by emotional exhaustion, cynicism, and low sense of personal accomplishment. ${ }^{1,2}$ Clinicians are prone to experience burnout more frequently than other occupations, as seen in the 2019 Medscape National Physician Burnout, Depression, \& Suicide Report which mentioned around $44 \%$ of physician reported feeling burnout. ${ }^{3,4}$ Residency may also contribute significantly to burnout, thereby affecting residents' clinical judgment, ability to communicate, and deliver high-quality care for patients. Moreover, burnout can also cause higher medical errors due to fatigue and reduced caution which may lead to negligence on personal safety measures and patient safety. ${ }^{3}$ Even though this topic has been increasingly discussed, the importance of addressing burnout becomes even clearer in the light of COVID-19 pandemic especially in Indonesia.

As cases in Indonesia continue to escalate, workload continue to increase and alter surgical residency training programs. Residents in Indonesia are at high risk of being infected with COVID-19, as they are also mobilized to assist in the mitigation of COVID-19 pandemic regardless of their specialty. At the same time, their chance in improving

\footnotetext{
* Corresponding author.

E-mail address: naylarahmadiani95@gmail.com (N. Rahmadiani).
} 
their surgical skills is also diminished, due to the reduced clinical and hands-on exposure as one of the safety measures for residents. All of these may cause physical, emotional, and emotional exhaustion for residents. ${ }^{5,6}$ Among the different specialties, surgical residents are prone to having higher rates of burnout. Studies prior to the COVID-19 pandemic have showed variable numbers regarding burnout in surgical residents, with one study found the burnout rate to be $73 \%$, much higher than other non-surgical specialties. ${ }^{7,8}$ Meanwhile, studies reporting the rate of burnout in surgical residents during COVID-19 are still scarce, Khalafallah et al. ${ }^{9}$ found the rate of burnout in neurosurgery residents to be $26.1 \%$, while Aziz et al. ${ }^{10}$ reported $33.1 \%$ more burnout in general surgery residents across the U.S. Other studies on the rate of burnout in medical residents during COVID-19 resulted in burnout rate of $76 \%{ }^{6}$

To our knowledge, there is no literature to date which describes burnout syndrome specifically in Indonesian surgical residents during COVID-19 pandemic. The aim of this study is to assess burnout syndrome in surgical residents of a tertiary referral hospital in Indonesia during COVID-19 pandemic.

\section{Methods}

A cross-sectional study was conducted on 120 surgical residents of a tertiary referral hospital in Indonesia in August 2020. Residents from the department of surgery and allied specialty (general surgery, orthopedic, and urology) are included in this study. Medical students, clerkship students, and attending physicians are excluded from the study. Total sampling method was used in this study. A period of one week was provided (9-15th of August 2020) for filling the questionnaire after a prior notification for the request of participation. A web-based questionnaire was used. Informed consent was obtained prior to filling the questionnaire. Anonymity of residents' identity is ensured. The study was performed according to the Declaration of Helsinki of the World Medical Association, and this study also has obtained approval from hospital's Ethics Committee prior to data collection from residents.

The questionnaire consisted of 29 items: 7 items were related to socio-demographic characteristics, academic and work-related factors, and 22 items were Indonesian version of Maslach Burnout Inventory Human Services Scale (MBI-HSS), which was already previously validated by other study. ${ }^{11}$ MBI-HSS has been suggested by previous studies as the "instrument of choice" for assessing burnout. ${ }^{12,13}$ Socio-demographic characteristics included age, gender, marital status, and living companion; academic and work-related factors include residency specialty, residency year, and working hours per week after COVID-19 pandemic. The question of emotional exhaustion (EE), depersonalization (DP), and sense of personal achievement (PA) was 7, 6 and 8 items respectively. Each item is measured using a 7-point Likert scale, from 0 (never) to 6 (every day). Each of the subscale scores were further classified as low, moderate, and high: low $\mathrm{EE}=0-18$, moderate $\mathrm{EE}=19-26$, high $\mathrm{EE} \geq 27$; low $\mathrm{DP}=0-5$, moderate $\mathrm{DP}=6-9$, high $\mathrm{DP}$ $\geq 10$; and low $\mathrm{PA} \geq 40$, moderate $\mathrm{PA}=34-39$, high $\mathrm{PA}=0-33$. Burnout is defined as exhibiting high $\mathrm{EE}$ (i.e. EE score $\geq 27$ ) or DP (i.e. DP score $\geq 10$ ), or low PA (i.e. PA score $\geq 40$ ). Burnout is defined as exhibiting high $\mathrm{EE}$ (i.e. $\mathrm{EE}$ score $\geq 27$ ) or DP (i.e. DP score $\geq 10$ ), or low PA (i.e. PA score $\geq 40)$. $^{3,14}$

Data regarding the socio-demographic characteristics, academic, and work-related factors of residents were obtained. ANOVA, KruskalWallis, Mann-Whitney, and independent $t$-test were used to compare means of each subscale of MBI-HSS to the socio-demographic, academic, and work-related factors, in accordance with the result of KolmogorovSmirnov test. Statistically significant results in data which had more than 2 groups were further analyzed using post-hoc test to determine which group had statistically significant difference. Cross-tabulation, chi-square, and Spearman correlation test were used to compare the classification of MBI-HSS subscale scores and presence of burnout with socio-demographic, academic, and work-related factors and determine the correlation of MBI-HSS subscale scores towards the sociodemographic factors. P-value $<0.05$ indicated statistical significance. Statistical analysis was carried out using SPSS version 23 (IBM Corp., Armonk, NY, USA).

\section{Results}

3.1. Socio-demographic characteristics, academic, and work-related factors of study participants

A total of 120 surgical residents had completed the questionnaire, which consisted of 51 orthopedic residents, 39 general surgery residents, and 30 urology residents. The detailed characteristics of study participants were presented in Table 1 . The participants were predominantly male $(90.8 \%)$, married $(81.7 \%)$, and did not stay with their family members during the residency $(57.5 \%)$. Most of the participants were in the 2 nd residency year (23.3\%), followed by those in the 4 th year (22.4\%), 5th year (21.7\%), 3rd year (18.3\%), and 1st year (14.2\%). Most of the residents worked for less than $70 \mathrm{~h}$ per week during the pandemic (57.5\%). General surgery residents tended to have longer working hours than residents of other specialties.

\subsection{Comparison between MBI-HSS subscale scores and socio- demographic, academic, and work-related factors}

Table 2 presented the comparison between mean of each subscale scores and all the identified factors, while Table 3 presented the overall subscale scores of the residents in this study. There was a statistically significant difference upon comparison of mean DP with marital status $(\mathrm{p}=0.010)$, in which married residents had higher mean DP compared to single residents. Residency specialty type yielded statistically significant differences upon comparison of mean EE and DP ( $p=0.000$ and $p$ $=0.003$, respectively). Post-hoc test revealed that general surgery specialty differed significantly with orthopedics and urology specialty ( $\mathrm{p}=$ 0.005 and $p=0.002$, respectively). Statistically significant difference in mean EE and DP were observed upon comparison with working hours ( $\mathrm{p}$ $=0.004$ and $\mathrm{p}=0.016$, respectively). Further post-hoc analysis revealed

Table 1

Socio-demographic characteristics, academic, and workrelated factors of study participants.

\begin{tabular}{ll}
\hline Variable & $\mathrm{N}(\%)$ \\
\hline Age & \\
24-29 years old & $41(34.2)$ \\
$30-34$ years old & $71(59.2)$ \\
$\quad \geq 35$ years old & $8(6.7)$ \\
Gender & $109(90.8)$ \\
$\quad$ Male & $11(9.2)$ \\
Female & \\
Marital Status & $22(18.3)$ \\
Single & $98(81.7)$ \\
Married & \\
Living Companion & $66(55)$ \\
without family & $54(45)$ \\
with family & \\
Residency Specialty & $39(32.5)$ \\
General surgery & $51(42.5)$ \\
Orthopedics & $30(25)$ \\
Urology & \\
Residency Year & $17(14.2)$ \\
1st year & $28(23.3)$ \\
2nd year & $22(18.3)$ \\
3rd year & $27(22.4)$ \\
4th year & $26(21.7)$ \\
5th year & \\
Working Hours & $69(57.5)$ \\
$<70$ h/week & $43(35.8)$ \\
70-100 h/week & $8(6.7)$ \\
\hline 100 h/week & \\
\hline &
\end{tabular}


Table 2

Comparison between mean of each subscale scores of MBI-HSS and socio-demographic, academic, and work-related factors.

\begin{tabular}{|c|c|c|c|c|c|c|c|c|c|}
\hline & \multicolumn{2}{|l|}{$\mathrm{EE}$} & \multirow[t]{2}{*}{$\mathrm{p}$-value } & \multicolumn{2}{|l|}{ DP } & \multirow[t]{2}{*}{ p-value } & \multicolumn{2}{|l|}{ PA } & \multirow[t]{2}{*}{$\mathrm{p}$-value } \\
\hline & Mean & SD & & Mean & SD & & Mean & SD & \\
\hline \multicolumn{10}{|l|}{ Age } \\
\hline $24-29$ yo & 14,59 & 11,70 & $0.865^{\mathrm{K}}$ & 4,59 & 5,43 & $0.974^{\mathrm{K}}$ & 35,54 & 8,43 & $0.594^{\mathrm{A}}$ \\
\hline $30-34$ уо & 13,28 & 10,53 & & 4,75 & 5,19 & & 36,85 & 8,97 & \\
\hline$\geq 35$ yo & 12,13 & 6,94 & & 3,25 & 1,67 & & 38,50 & 6,44 & \\
\hline \multicolumn{10}{|l|}{ Gender } \\
\hline Male & 13,33 & 10,70 & $0.231^{\mathrm{M}}$ & 4,58 & 5,14 & $0.829^{\mathrm{M}}$ & 36,48 & 8,61 & $0.901^{\mathrm{t}}$ \\
\hline Female & 16,82 & 10,71 & & 4,73 & 4,98 & & 36,82 & 9,18 & \\
\hline \multicolumn{10}{|l|}{ Marital Status } \\
\hline Single & 10,45 & 8,50 & $0.160^{\mathrm{M}}$ & 2,18 & 3,03 & $0.010^{\mathrm{M}}$ & 36,05 & 9,76 & $0.782^{t}$ \\
\hline Married & 14,37 & 11,05 & & 5,13 & 5,32 & & 36,61 & 8,40 & \\
\hline \multicolumn{10}{|l|}{ Living Companion } \\
\hline Without family & 13,55 & 10,35 & $0.945^{\mathrm{M}}$ & 4,68 & 4,88 & $0.553^{\mathrm{M}}$ & 36,52 & 7,36 & $0.993^{t}$ \\
\hline With family & 13,78 & 11,22 & & 4,48 & 5,41 & & 36,50 & 10,02 & \\
\hline \multicolumn{10}{|l|}{ Residency Specialty } \\
\hline General surgery & 19,59 & 11,55 & $<0.001^{\mathrm{K}}$ & 6,92 & 6,01 & $0.003^{\mathrm{K}}$ & 35,38 & 9,02 & $0.384^{\mathrm{A}}$ \\
\hline Orthopedics & 11,24 & 10,31 & & 3,84 & 4,67 & & 36,33 & 9,18 & \\
\hline Urology & 10,03 & 6,40 & & 2,83 & 3,23 & & 38,27 & 6,96 & \\
\hline \multicolumn{10}{|l|}{ Residency Year } \\
\hline 1st year & 18,65 & 14,59 & $0.082^{\mathrm{K}}$ & 6,53 & 6,98 & $0.424^{\mathrm{K}}$ & 34,88 & 8,27 & $0.404^{\mathrm{A}}$ \\
\hline 2nd year & 16,96 & 12,50 & & 4,64 & 5,11 & & 37,61 & 7,69 & \\
\hline 3rd year & 8,18 & 6,42 & & 3,18 & 3,86 & & 37,95 & 8,29 & \\
\hline 4th year & 12,56 & 8,12 & & 4,04 & 4,59 & & 37,52 & 8,75 & \\
\hline 5 th year & 12,58 & 8,91 & & 5,04 & 5,02 & & 34,12 & 9,84 & \\
\hline \multicolumn{10}{|l|}{ Working Hours } \\
\hline$<70 \mathrm{~h} /$ week & 10,65 & 7,92 & $0.004^{\mathrm{K}}$ & 3,33 & 3,84 & $0.016^{\mathrm{K}}$ & 37,43 & 8,39 & $0.265^{\mathrm{A}}$ \\
\hline 70-100 h/week & 16,74 & 12,31 & & 6,12 & 6,00 & & 34,79 & 9,36 & \\
\hline$>100 \mathrm{~h} /$ week & 22,88 & 13,60 & & 7,25 & 6,69 & & 37,75 & 5,12 & \\
\hline
\end{tabular}

$\mathrm{SD}=$ standard deviation.

${ }^{\text {A }}$ ANOVA test; ${ }^{\mathrm{K}}$ Kruskal-Wallis test; ${ }^{\mathrm{t}}$ independent $t$-test; ${ }^{\mathrm{M}}$ Mann-Whitney test.

Bold case indicates statistical significancy $(\mathrm{p}<0.05)$.

Table 3

Overall EE, DP, and PA scores of Surgical Residents in The Study.

\begin{tabular}{|c|c|c|c|c|c|c|}
\hline & \multicolumn{2}{|l|}{$\mathrm{EE}$} & \multicolumn{2}{|l|}{ DP } & \multicolumn{2}{|l|}{ PA } \\
\hline & $\mathrm{N}$ & $\%$ & $\mathrm{~N}$ & $\%$ & $\mathrm{~N}$ & $\%$ \\
\hline Low & 87 & $72.50 \%$ & 81 & $67.50 \%$ & 52 & $43.33 \%$ \\
\hline Moderate & 18 & $15.00 \%$ & 23 & $19.17 \%$ & 31 & $25.83 \%$ \\
\hline High & 15 & $12.50 \%$ & 16 & $13.33 \%$ & 37 & $30.83 \%$ \\
\hline Overall mean \pm SD & \multicolumn{2}{|c|}{$13.65 \pm 10.66$} & \multicolumn{2}{|c|}{$4.59 \pm 5.08$} & \multicolumn{2}{|c|}{$36.5 \pm 8.59$} \\
\hline
\end{tabular}

that mean EE in those who worked for less than $70 \mathrm{~h}$ per week differed significantly with both $70-100 \mathrm{~h}$ per week and more than $100 \mathrm{~h}$ per week group ( $p=0.011$ and $p=0.009)$. On the other hand, mean DP in residents working less than $70 \mathrm{~h}$ per week differed with residents working for $70-100 \mathrm{~h}$ per week $(\mathrm{p}=0.011)$.

\subsection{Comparison \& correlation between MBI-HSS subscale scores and socio-demographic, academic, and work-related factors}

Table 4 contained the comparison between all the subscale scores and the evaluated factors. In this study, most of the residents had low EE ( $n=87,72.5 \%)$, followed by those with moderate $\mathrm{EE}(\mathrm{n}=18,15 \%)$, and high EE ( $\mathrm{n}=15,12.5 \%)$. There were statistically significant differences in the marital status, residency specialty, year of residency, and working hour factor (p-value of $0.048,0.004,0.021$, and 0.001 , respectively) upon comparison between EE classification and socio-demographic, academic, and work-related factors. Residents who were single had a slightly lower tendency to have low EE, compared to those who were married. Interestingly, all the residents with high EE were married. General surgery residents tended to have high EE, while orthopedics and urology residents tended to have low EE. Residents of higher academic year (senior residents) tended to have low EE compared to those in their early years of residency (1st or 2nd year). It was also found that residents who worked for less than $70 \mathrm{~h}$ per week were found to have mostly low

or moderate EE. Meanwhile, those who worked between 70 and $100 \mathrm{~h}$ per week were found to have high EE. However, upon correlation test, EE correlated significantly only with residency specialty and working hours ( $p$ value of $<0.001$ and 0.001 , respectively). Overall, general surgery residents tended to have higher EE score rather than orthopedic and urology residents. Higher EE score was correlated with more working hours per week, vice versa.

Most of the residents in the study had low DP $(n=81,67.5 \%)$, followed by those with moderate DP $(n=23,19.17 \%)$ and high DP $(n=16$, $13.33 \%$ ). There were significant differences between the classification of DP and residency specialty as well as working hours ( $\mathrm{p}=0.039$ and 0.017, respectively). Many of the residents with high DP were found in the general surgery specialty, compared to other specialties. Most of the residents who worked $70-100 \mathrm{~h}$ per week had moderate and high DP. However, it was found that DP score was also correlated with marital status aside from residency specialty and working hours ( $\mathrm{p}$ value of $0.009,0.001$, and 0.004 , respectively). Married residents correlated with higher DP compared to those who were single. General surgery residents tended to have higher DP score rather than orthopedic and urology residents. Higher DP score was correlated with more working hours per week, vice versa.

Most of the residents had low PA $(n=52,43.33 \%)$, followed by those with high and moderate PA ( $\mathrm{n}=37,20.83 \%$ and $\mathrm{n}=31,25.83 \%$, respectively). None of the socio-demographic, academic, and workrelated factors have statistically significant difference in comparison with PA classification. There was also no correlation found between PA score and any of the socio-demographic factors. Statistically significant correlations were presented in Fig. 1.

\subsection{Comparison between the presence of burnout and socio-demographic, academic, and work-related factors}

Among the 120 residents in this study, there were 68 residents (56.67\%) who experienced burnout. Table 5 presented the comparison 
Table 4

Comparison between EE, DP, and PA subscale scores and socio-demographic, academic, and work-related factors.

\begin{tabular}{|c|c|c|c|c|c|c|c|c|c|c|c|c|c|c|c|c|c|c|c|c|c|}
\hline \multirow{3}{*}{ Age } & \multicolumn{6}{|c|}{ EE Classification (N, \%) } & \multirow[t]{3}{*}{$\mathrm{p}$-value } & \multicolumn{6}{|c|}{ DP Classification (N, \%) } & \multirow[t]{3}{*}{$\mathrm{p}$-value } & \multicolumn{6}{|c|}{ PA Classification (N, \%) } & \multirow[t]{2}{*}{$\mathrm{p}$-value } \\
\hline & \multicolumn{2}{|c|}{ Low } & \multicolumn{2}{|c|}{ Moderate } & \multicolumn{2}{|c|}{ High } & & \multicolumn{2}{|c|}{ Low } & \multicolumn{2}{|c|}{ Moderate } & \multicolumn{2}{|c|}{ High } & & \multicolumn{2}{|c|}{ Low } & \multicolumn{2}{|c|}{ Moderate } & \multicolumn{2}{|c|}{ High } & \\
\hline & & & & & & & & & & & & & & & & & & & & & \\
\hline 24-29 yo & 29 & $33,3 \%$ & 5 & $27,8 \%$ & 7 & $46,7 \%$ & 0.634 & 26 & $32,1 \%$ & 11 & $47,8 \%$ & 4 & $25,0 \%$ & 0.116 & 17 & $32,7 \%$ & 9 & $29,0 \%$ & 15 & $40,5 \%$ & 0.823 \\
\hline 30-34 yo & 52 & $59,8 \%$ & 11 & $61,1 \%$ & 8 & $53,3 \%$ & & 47 & $58,0 \%$ & 12 & $52,2 \%$ & 12 & $75,0 \%$ & & 32 & $61,5 \%$ & 19 & $61,3 \%$ & 20 & $54,1 \%$ & \\
\hline$\geq 35$ yo & 6 & $6,9 \%$ & 2 & $11,1 \%$ & 0 & $0,0 \%$ & & 8 & $9,9 \%$ & 0 & $0,0 \%$ & 0 & $0,0 \%$ & & 3 & $5,8 \%$ & 3 & $9,7 \%$ & 2 & $5,4 \%$ & \\
\hline \multicolumn{22}{|l|}{ Gender } \\
\hline Male & 81 & $93,1 \%$ & 14 & $77,8 \%$ & 14 & $93,3 \%$ & 0.114 & 74 & $91,4 \%$ & 21 & $91,3 \%$ & 14 & $87,5 \%$ & 0.884 & 46 & $88,5 \%$ & 29 & $93,5 \%$ & 34 & $91,9 \%$ & 0.713 \\
\hline Female & 6 & $6,9 \%$ & 4 & $22,2 \%$ & 1 & $6,7 \%$ & & 7 & $8,6 \%$ & 2 & $8,7 \%$ & 2 & $12,5 \%$ & & 6 & $11,5 \%$ & 2 & $6,5 \%$ & 3 & $8,1 \%$ & \\
\hline \multicolumn{22}{|l|}{ Marital Status } \\
\hline Single & 16 & $18,4 \%$ & 6 & $33,3 \%$ & 0 & $0,0 \%$ & 0.048 & 18 & $22,2 \%$ & 3 & $13,0 \%$ & 1 & $6,3 \%$ & 0.246 & 9 & $17,3 \%$ & 4 & $12,9 \%$ & 9 & $24,3 \%$ & 0.464 \\
\hline Married & 71 & $81,6 \%$ & 12 & $66,7 \%$ & 15 & $100,0 \%$ & & 63 & $77,8 \%$ & 20 & $87,0 \%$ & 15 & $93,8 \%$ & & 43 & $82,7 \%$ & 27 & $87,1 \%$ & 28 & $75,7 \%$ & \\
\hline \multicolumn{22}{|l|}{ Living Companion } \\
\hline Without family & 46 & $52,9 \%$ & 13 & $72,2 \%$ & 7 & $46,7 \%$ & 0.254 & 45 & $55,6 \%$ & 10 & $43,5 \%$ & 11 & $68,8 \%$ & 0.291 & 26 & $50,0 \%$ & 19 & $61,3 \%$ & 21 & $56,8 \%$ & 0.587 \\
\hline With family & 41 & $47,1 \%$ & 5 & $27,8 \%$ & 8 & $53,3 \%$ & & 36 & $44,4 \%$ & 13 & $56,5 \%$ & 5 & $31,3 \%$ & & 26 & $50,0 \%$ & 12 & $38,7 \%$ & 16 & $43,2 \%$ & \\
\hline \multicolumn{22}{|l|}{ Residency Specialty } \\
\hline General surgery & 21 & $24,1 \%$ & 7 & $38,9 \%$ & 11 & $73,3 \%$ & 0.004 & 21 & $25,9 \%$ & 8 & $34,8 \%$ & 10 & $62,5 \%$ & 0.039 & 16 & $30,8 \%$ & 10 & $32,3 \%$ & 13 & $35,1 \%$ & 0.240 \\
\hline Orthopedics & 40 & $46,0 \%$ & 7 & $38,9 \%$ & 4 & $26,7 \%$ & & 35 & $43,2 \%$ & 11 & $47,8 \%$ & 5 & $31,3 \%$ & & 24 & $46,2 \%$ & 9 & $29,0 \%$ & 18 & $48,6 \%$ & \\
\hline Urology & 26 & $29,9 \%$ & 4 & $22,2 \%$ & 0 & $0,0 \%$ & & 25 & $30,9 \%$ & 4 & $17,4 \%$ & 1 & $6,3 \%$ & & 12 & $23,1 \%$ & 12 & $38,7 \%$ & 6 & $16,2 \%$ & \\
\hline \multicolumn{22}{|l|}{ Residency Year } \\
\hline 1st year & 9 & $10,3 \%$ & 3 & $16,7 \%$ & 5 & $33,3 \%$ & 0.021 & 10 & $12,3 \%$ & 4 & $17,4 \%$ & 3 & $18,8 \%$ & 0.586 & 5 & $9,6 \%$ & 6 & $19,4 \%$ & 6 & $16,2 \%$ & 0.652 \\
\hline 2nd year & 16 & $18,4 \%$ & 5 & $27,8 \%$ & 7 & $46,7 \%$ & & 16 & $19,8 \%$ & 8 & $34,8 \%$ & 4 & $25,0 \%$ & & 12 & $23,1 \%$ & 9 & $29,0 \%$ & 7 & $18,9 \%$ & \\
\hline 3rd year & 21 & $24,1 \%$ & 1 & $5,6 \%$ & 0 & $0,0 \%$ & & 16 & $19,8 \%$ & 5 & $21,7 \%$ & 1 & $6,3 \%$ & & 12 & $23,1 \%$ & 3 & $9,7 \%$ & 7 & $18,9 \%$ & \\
\hline 4th year & 20 & $23,0 \%$ & 5 & $27,8 \%$ & 2 & $13,3 \%$ & & 19 & $23,5 \%$ & 3 & $13,0 \%$ & 5 & $31,3 \%$ & & 14 & $26,9 \%$ & 5 & $16,1 \%$ & 8 & $21,6 \%$ & \\
\hline 5th year & 21 & $24,1 \%$ & 4 & $22,2 \%$ & 1 & $6,7 \%$ & & 20 & $24,7 \%$ & 3 & $13,0 \%$ & 3 & $18,8 \%$ & & 9 & $17,3 \%$ & 8 & $25,8 \%$ & 9 & $24,3 \%$ & \\
\hline \multicolumn{22}{|l|}{ Working Hours } \\
\hline$<70 \mathrm{~h} /$ week & 57 & $65,5 \%$ & 11 & $61,1 \%$ & 1 & $6,7 \%$ & 0.001 & 53 & $65,4 \%$ & 11 & $47,8 \%$ & 5 & $31,3 \%$ & 0.017 & 31 & $59,6 \%$ & 19 & $61,3 \%$ & 19 & $51,4 \%$ & 0.750 \\
\hline 70-100 h/week & 26 & $29,9 \%$ & 6 & $33,3 \%$ & 11 & $73,3 \%$ & & 23 & $28,4 \%$ & 12 & $52,2 \%$ & 8 & $50,0 \%$ & & 18 & $34,6 \%$ & 9 & $29,0 \%$ & 16 & $43,2 \%$ & \\
\hline$>100 \mathrm{~h} /$ week & 4 & $4,6 \%$ & 1 & $5,6 \%$ & 3 & $20,0 \%$ & & 5 & $6,2 \%$ & 0 & $0,0 \%$ & 3 & $18,8 \%$ & & 3 & $5,8 \%$ & 3 & $9,7 \%$ & 2 & $5,4 \%$ & \\
\hline
\end{tabular}

Statistical significancy was determined using Chi-square test.

Bold case indicates statistical significancy $(\mathrm{p}<0.05)$. 

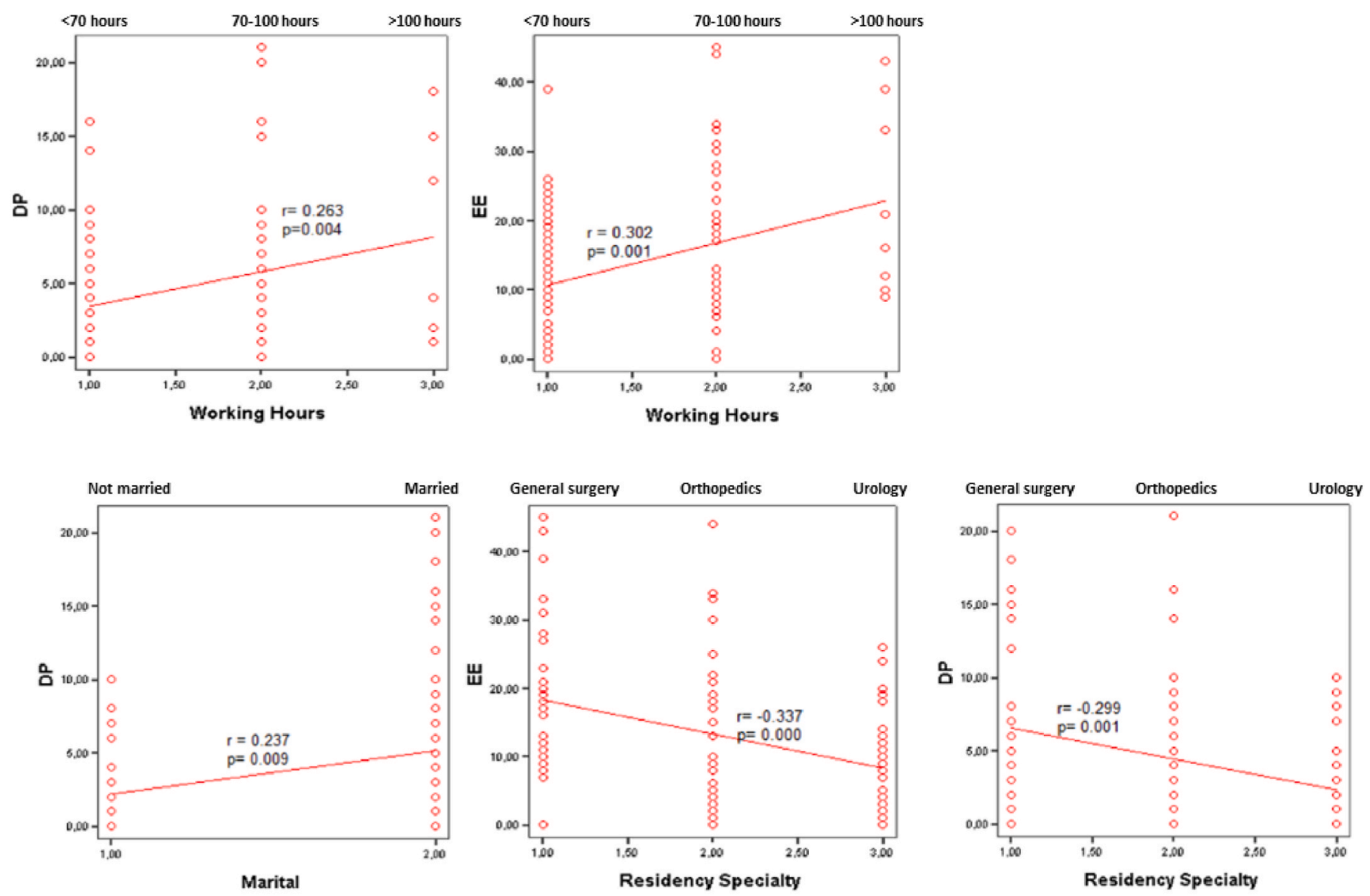

Correlation was assessed using Spearman's correlation test.

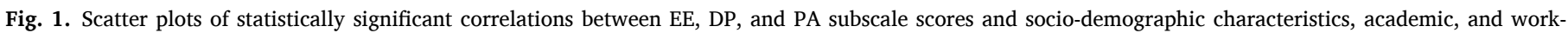
related factors.

between the presence of burnout and the related factors. There were statistically significant differences in the working hour factor ( $\mathrm{p}$ value of 0.017), upon comparison with the presence of burnout. Residents who worked for less than $70 \mathrm{~h}$ per week tended to not experience burnout, while those who worked for $70-100$ and more than $100 \mathrm{~h}$ per week were found to experience more burnout.

\section{Discussion}

Several studies have stated that during COVID-19 pandemic, the burnout rate among healthcare workers were increased. Residents are among those who were impacted. In our center, residents are also being deployed in the battle against COVID-19, irrespective of their specialty. Thus, albeit surgical cases and working hours may be diminished, surgical residents still have high risk of contracting COVID-19 as cases in Indonesia continue to escalate. This greatly alters resident training program and may act as a potential source of burnout for residents. ${ }^{2,3,5,13,15}$ Prior to the pandemic, burnout rates in residency varied greatly among studies, ranging from $18 \%$ to $82 \%{ }^{16}$ Surgical residents are also prone to having higher rates of burnout. A study by Malik et al. ${ }^{7}$ found the rate of burnout to be as high as $57.9 \%$, and another study by Serenari et al. ${ }^{8}$ showed a staggering rate of $73 \%$ in surgical specialties compared to those attending non-surgical specialties (56.3\%). Studies reporting the rate of burnout in surgical residents during COVID-19 are still scarce. Several studies on the surgery residents reported a burnout rate of $26.1 \%-33.1 \%{ }^{9,10}$ Other studies on the rate of burnout in residents and physician trainee during COVID-19 resulted in a high burnout rate. ${ }^{6,17}$ This study found a higher rate of burnout
(56.67\%) in the surgical residents during COVID-19 pandemic, compared to those reported in the literature.

Burnout rates across surgery specialties varied among studies. To date, there has been no study specifically addressing the correlation of different surgical specialties with burnout in residents, both in normal and COVID-19 pandemic setting. Medscape's 2019 National Physician Burnout, Depression, \& Suicide Reports found that urology specialty has the highest rate of burnout (54\%), while general surgery and orthopedics have lower burnout rates (46\% and $38 \%$, respectively). ${ }^{4}$ Studies comparing different surgical specialties and burnout have varying methods. A study in 2001 comparing general and orthopedic surgeons found relatively high degrees of burnout among the two specialties, with $32 \%$ of participants had high EE, $13 \%$ had high DP, and $4 \%$ had low PA. Another study in 2011 of multiple surgical specialties found that Trauma surgeon had the highest rate of burnout (51.6\%), compared to other specialties such as urology and orthopedics (43\% and $32 \%$, respectively). A meta-analysis of burnout in surgeons have mentioned that orthopedics experienced moderate level of EE and DP compared to other specialties, and that general surgery was one of the specialties which showed significantly higher rates of burnout on all three subscales. ${ }^{18-20}$ Our study showed that among residents in this study who experienced burnout, most of them were general surgery residents (47.4\%), followed by orthopedics, and urology residents (38.6\% and $14 \%$, respectively).

The correlation between working hours and burnout rate are still inconclusive. Several studies mentioned that strong correlation exists between the two particularly during COVID-19 pandemic in relation to increased workload, while on the other hand other studies suggested that there were no significant effects of working hours towards burnout 
Table 5

Comparison between the presence of burnout and socio-demographic, academic, and work-related factors.

\begin{tabular}{|c|c|c|c|c|c|}
\hline & \multicolumn{4}{|c|}{ BURNOUT (N, \%) } & \multirow[t]{2}{*}{ p-value } \\
\hline & \multicolumn{2}{|c|}{ Absent } & \multicolumn{2}{|c|}{ Present } & \\
\hline \multicolumn{6}{|l|}{ Age } \\
\hline 24-29 years old & 18 & $34,6 \%$ & 23 & $33,8 \%$ & 0.501 \\
\hline 30-34 years old & 29 & $55,8 \%$ & 42 & $61,8 \%$ & \\
\hline$\geq 35$ years old & 5 & $9,6 \%$ & 3 & $4,4 \%$ & \\
\hline \multicolumn{6}{|l|}{ Gender } \\
\hline Male & 48 & $92,3 \%$ & 61 & $89,7 \%$ & 0.625 \\
\hline Female & 4 & $7,7 \%$ & 7 & $10,3 \%$ & \\
\hline \multicolumn{6}{|l|}{ Marital Status } \\
\hline Single & 13 & $25,0 \%$ & 9 & $13,2 \%$ & 0.099 \\
\hline Married & 39 & $75,0 \%$ & 59 & $86,8 \%$ & \\
\hline \multicolumn{6}{|l|}{ Living Companion } \\
\hline Without family & 29 & $55,8 \%$ & 37 & $54,4 \%$ & 0.882 \\
\hline With family & 23 & $44,2 \%$ & 31 & $45,6 \%$ & \\
\hline \multicolumn{6}{|l|}{ Residency Specialty } \\
\hline General surgery & 13 & $25,0 \%$ & 26 & $38,2 \%$ & 0.079 \\
\hline Orthopedics & 21 & $40,4 \%$ & 30 & $44,1 \%$ & \\
\hline Urology & 18 & $34,6 \%$ & 12 & $17,6 \%$ & \\
\hline \multicolumn{6}{|l|}{ Residency Year } \\
\hline 1st year & 7 & $13,5 \%$ & 10 & $14,7 \%$ & 0.651 \\
\hline 2nd year & 13 & $25,0 \%$ & 15 & $22,1 \%$ & \\
\hline 3rd year & 9 & $17,3 \%$ & 13 & $19,1 \%$ & \\
\hline 4th year & 9 & $17,3 \%$ & 18 & $26,5 \%$ & \\
\hline 5 th year & 14 & $26,9 \%$ & 12 & $17,6 \%$ & \\
\hline \multicolumn{6}{|l|}{ Working Hours } \\
\hline Less than $70 \mathrm{~h} /$ week & 34 & $65,4 \%$ & 35 & $51,5 \%$ & 0.017 \\
\hline 70-100 h/week & 15 & $28,8 \%$ & 28 & $41,2 \%$ & \\
\hline More than $100 \mathrm{~h} /$ week & 3 & $5,8 \%$ & 5 & $7,4 \%$ & \\
\hline
\end{tabular}

Statistical significancy was determined using Chi-square test.

Bold case indicates statistical significancy $(\mathrm{p}<0.05)$.

subscale scores. ${ }^{21-23}$ Our study corroborates the notion that working hours may have significant correlation with burnout, as high EE and DP were positively correlated with higher working hours in COVID-19 pandemic setting.

Residency year might be associated with rates of burnout. Some studies conducted during COVID-19 pandemic suggest that individuals in the initial years of residency experienced more burnout than their seniors. A study on neurosurgery residents mentioned that residency year was negatively associated with burnout, and with every 1-year increase in the level, there was a $33.2 \%$ reduction in burnout rate. ${ }^{9,10}$ Accordingly, our study showed the tendency of high EE score in junior residents (lower academic year) compared to senior residents. In the light of COVID-19 pandemic, burnout on healthcare workers has become a growing topic of interest of many studies, and resident is an integral part in the battle against COVID-19. It is imperative to formulate appropriate strategies to prevent and manage burnout in residents. Organizational and social support, clear communication, and developing sense of control were suggested to be some of the protective factors essential in mitigating adverse mental health outcomes during pandemic. $^{17}$

Meanwhile, our study found neither significant differences upon comparison nor significant correlation between burnout and age, gender, and living companion. However, marital status was found to be an important factor in burnout. Our study revealed that married residents were prone to having high EE and DP, in contrast to a recent study on surgical residents, fellows, and early-career surgeons which reported that female were more likely to experience burnout, and that age and marital status were not significant factors involved in burnout. Nevertheless, one study among healthcare workers (health technicians, physicians, nurses, pharmacist, psychologist, nutritionist, and healthcare assistants) stated that there was significantly less personal burnout in single residents rather than those who were married. Several older studies prior to COVID-19 pandemic stated that there were no significant differences observed in age, gender, and living companion, however another study in 2018 on orthopedic and trauma surgery residents in France suggested that significant risk factors for burnout include living without a partner, while male gender tends to be a protective factor. ${ }^{22-26}$

Understanding residents' point of view in facing this pandemic might shed some lights in formulating the best course of actions. It is also important to remember that burnout is a multifactorial condition, therefore, assessing the factors involved in its occurrence is essential. Addressing residents' concerns should be a priority. Residents should gain a sense of safety and security amidst this pandemic, as they have a unique situation of having to keep the balance between service and education. Residents-centered approach in tackling this issue seems to be the way forward. There are various ways in achieving this, such as establishing relevant regulations and guidelines surrounding COVID-19 for residents, providing adequate protective personal equipment (PPE), training on PPE-donning and doffing procedures, creating safe and secure workplace environment to minimize risk of infection, promoting safe operating room practices, regulating effective and efficient working shifts, providing facilities for residents' testing and treatment, establishing accessible COVID-19 response center for residents which also offers psychological support, actively monitoring the overall well-being of residents and encouraging them to not hesitate to utilize psychological services provided, organizing workshops regarding stress management and coping strategies, and conducting virtual teaching using various methods to compensate with reduced academic and surgical experience. $5,6,10,15,27,28$

There are several limitations of this study. This is a single-center study with a relatively small number of subjects; therefore, the results must be taken in the context of the study population. Uneven population distribution, such as the very small number of female residents across surgical specialties in our center may affect the results of this study. However, our total sampling method minimizes bias caused by low response rate, therefore our data may provide the "whole picture" of the residents across different surgical specialties in our center. Residents might choose the perceived "desired/expected" answers or be compelled to choose "neutral" or even the extreme ends of the scale only, therefore response biases may potentially occur, despite the efforts of minimizing them using a standardized burnout scale, ensuring the confidentiality of data collection, and provide transparency in the way the data will be used. Potential confounding factors include other traumatic experiences or other stressors near the time of the survey, which were not assessed in this study. As COVID-19 cases in Indonesia fluctuates, the authors recognized that the results may be influenced by the time in which the study was conducted. Furthermore, due to the cross-sectional nature of this study, a definitive causality or association cannot be ascertained. Nevertheless, this is the first study of its kind in Indonesia, which provides invaluable insights regarding burnout in surgical-related specialties from a tertiary referral teaching hospital in the face of COVID-19 pandemic. Future larger-scale studies regarding this matter are warranted.

\section{Conclusion}

This study showed that burnout is a major issue in surgical residents during COVID-19 pandemic and may be associated with certain sociodemographic, academic, and work-related factors. Future larger-scale studies to assess potential risk and protective factors contributing to burnout in Indonesian residents during different time points within COVID-19 pandemic are much needed. These studies may provide insights in developing strategies to improve resident training program, increasing our understanding regarding the scope of this issue, as well as preventing and addressing burnout.

\section{Funding source}

No funding source to be declared. 


\section{Ethical approval}

Ethical approval was obtained from Saiful Anwar Hospital's Research Ethics Committee: No. 400/177/K.3/302/2020.

\section{Declaration of competing interest}

The authors declare no conflict of interest.

\section{References}

1 Elmore L, Jeffe D, Jin L, Awad M, Turnbull I. National survey of burnout among US general surgery residents. J Am Coll Surg. 2016;223(3):440-451. https://doi.org/ 10.1016/j.jamcollsurg.2016.05.014.

2 Dyrbye L, Shanafelt T. A narrative review on burnout experienced by medical students and residents. Med Educ. 2015;50(1):132-149. https://doi.org/10.1111/ medu.12927 [.

3 Dimitriu M, Pantea-Stoian A, Smaranda A, et al. Burnout syndrome in Romanian medical residents in time of the COVID-19 pandemic. Med Hypotheses. 2020;144: 109972. https://doi.org/10.1016/j.mehy.2020.109972.

4 Kane L. Medscape National Physician Burnout, Depression \& Suicide Report; 2019 [Internet]. Medscape. 2021 [cited 27 December 2020]. Available from: https://www.medscape.com/slidesh ow/2019-lifestyle-burnout-depression-6011056\#3.

5 Ong A. Impact of COVID-19 on medical education and resident burnout in a postgraduate programme. Singap Med J. 2020. https://doi.org/10.11622/ smedj. 2020100.

6 Osama M, Zaheer F, Saeed H, et al. Impact of COVID-19 on surgical residency programs in Pakistan; A residents' perspective. Do programs need formal restructuring to adjust with the "new normal"? A cross-sectional survey study. Int $J$ Surg. 2020;79:252-256. https://doi.org/10.1016/j.ijsu.2020.06.004.

7 Malik A, Bhatti S, Shafiq A, et al. Burnout among surgical residents in a lower-middle income country - are we any different? Ann Med Surg. 2016;9:28-32. https://doi. org/10.1016/j.amsu.2016.05.012.

8 Serenari M, Cucchetti A, Russo P, et al. Burnout and psychological distress between surgical and non-surgical residents. Updates Surg. 2019;71(2):323-330. https://doi. org/10.1007/s13304-019-00653-0.

9 Khalafallah A, Lam S, Gami A, et al. A national survey on the impact of the COVID-19 pandemic upon burnout and career satisfaction among neurosurgery residents. $J$ Clin Neurosci. 2020;80:137-142. https://doi.org/10.1016/j.jocn.2020.08.012.

10 Aziz H, James T, Remulla D, et al. Effect of COVID-19 on surgical training across the United States: a national survey of general surgery residents. J Surg Educ. 2021;78(2): 431-439. https://doi.org/10.1016/j.jsurg.2020.07.037.

11 Yulianto H. Maslach Burnout Inventory-Human Services Survey (MBI-HSS) Versi Bahasa Indonesia: Studi Validasi Konstruk Pada Anggota Polisi. 9. Jurnal Pengukuran Psikologi dan Pendidikan Indonesia; 2020:19-29. https://doi.org/10.15408/jp3i.v9i1.13329 (JP3I) [Indonesian].

12 Leiter M, Maslach C, Frame K. Burnout Encycl Clinic. Psychol. 2015:1-7. https://doi. org/10.1002/9781118625392.wbecp142.
13 Amanullah S, Ramesh Shankar R. The impact of COVID-19 on physician burnout globally: a review. Healthcare. 2020;8(4):421. https://doi.org/10.3390/ healthcare8040421.

14 Wang C, Grassau P, Lawlor P, et al. Burnout and resilience among Canadian palliative care physicians. BMC Palliat Care. 2020;19(169). https://doi.org/10.1186/ s12904-020-00677-z.

15 Romanelli J, Gee D, Mellinger J, et al. The COVID-19 reset: lessons from the pandemic on Burnout and the Practice of Surgery. Surg Endosc. 2020;34(12): 5201-5207. https://doi.org/10.1007/s00464-020-08072-8 [.

16 Willems R, Monten C, Portzky G. Exploring the relative importance of workorganizational burnout risk factors in Belgian residents. Med Educ Online. 2018;23 (1):1521246. https://doi.org/10.1080/10872981.2018.1521246.

17 Kannampallil T, Goss C, Evanoff B, Strickland J, McAlister R, Duncan J. Exposure to COVID-19 patients increases physician trainee stress and burnout. PLOS One. 2020;15 (8), e0237301. https://doi.org/10.1371/journal.pone.0237301.

18 Dimou F, Eckelbarger D, Riall T. Surgeon burnout: a systematic review. J Am Coll Surg. 2016;222(6):1230-1239. https://doi.org/10.1016/j.jamcollsurg.2016.03.022.

19 Balch C, Shanafelt T, Sloan J, Satele D, Freischlag J. Distress and career satisfaction among 14 surgical specialties, comparing academic and private practice settings. Ann Surg. 2011;254(4):558-568. https://doi.org/10.1097/SLA.0b013e318230097e.

20 Bartholomew A, Houk A, Pulcrano M, et al. Meta-analysis of surgeon burnout syndrome and specialty differences. J Surg Educ. 2018;75(5):1256-1263. https://doi. org/10.1016/j.jsurg.2018.02.003.

21 Balch C, Shanafelt T, Sloan J, Satele D, Kuerer H. Burnout and career satisfaction among surgical oncologists compared with other surgical specialties. Ann Surg Oncol. 2010;18(1):16-25. https://doi.org/10.1245/s10434-010-1369-5 [.

22 Dinibutun S. Factors associated with burnout among physicians: an evaluation during A period of COVID-19 pandemic. J Healthc Leader. 2020;12:85-94. https:// doi.org/10.2147/JHL.S270440.

23 Coleman J, Abdelsattar J, Glocker R, et al. COVID-19 pandemic and the lived experience of surgical residents, fellows, and early-career surgeons in the American college of surgeons. J Am Coll Surg. 2021;232(2):119-135. https://doi.org/10.1016/ j.jamcollsurg.2020.09.026. e20.

24 Duarte I, Teixeira A, Castro L, et al. Burnout among Portuguese healthcare workers during the COVID-19 pandemic. BMC Publ Health. 2020;20(1). https://doi.org/ 10.1186/s12889-020-09980-z].

25 Rosas-Navarro J, Covarrubias-Castillo S, Villalobos-Lizardi J, Muñoz-Chacón D, Bazúa O'Connor R. Association between Burnout Syndrome and medical training by specialty in first-year residents. Salud Ment. 2020;43(5):227-233. https://doi.org/ 10.17711/sm.0185-3325.2020.031.

26 Faivre G, Kielwasser H, Bourgeois M, Panouilleres M, Loisel F, Obert L. Burnout syndrome in orthopaedic and trauma surgery residents in France: a nationwide survey. J Orthop Traumatol: Surg Res. 2018;104(8):1291-1295. https://doi.org/ 10.1016/j.otsr.2018.08.016.

27 Gundavda K, Patkar S, Gulia A. Surgical oncology residents' perspective in the COVID-19 pandemic: standing at crossroads. Indian J Med Sci. 2021;73:66-69. https://doi.org/10.25259/IJMS 3752020.

$28 \mathrm{He}$ K, Stolarski A, Whang E, Kristo G. Addressing general surgery residents' concerns in the early phase of the COVID-19 pandemic. J Surg Educ. 2020;77(4):735-738. https://doi.org/10.1016/j.jsurg.2020.04.003. 